\title{
The second Summer Youth Olympic Games in Nanjing, People's Republic of China: preparing youth athletes to compete in the heat
}

This article was published in the following Dove Press journal:

Open Access Journal of Sports Medicine

I September 2014

Number of times this article has been viewed

\begin{abstract}
Joao Brito'
Sebastien Racinais ${ }^{2}$

George P Nassis ${ }^{1,3}$

'National Sports Medicine Programme, Excellence in Football Project, Aspetar - Qatar Orthopaedic and Sports Medicine Hospital, Doha, Qatar; ${ }^{2}$ Athlete Health and Performance Research Centre, Aspetar - Qatar Orthopaedic and Sports Medicine Hospital, Doha, Qatar; ${ }^{3}$ School of Physical Education and Sport Science, National and Kapodistrian University of Athens, Athens, Greece
\end{abstract}

All authors contributed equally to this manuscript
Correspondence: George P Nassis Aspetar - Qatar Orthopaedic and Sports Medicine Hospital, National Sports Medicine Programme, Excellence in Football Project, PO Box 29222, Doha, Qatar

Tel +97444 I32650

Email george.nassis@aspetar.com
Abstract: The second Summer Youth Olympic Games will take place August 16-28, 2014 in Nanjing, People's Republic of China during the peak of the summer. Nanjing has been reported as one of the hottest cities in the People's Republic of China, with temperatures reaching as high as $40^{\circ} \mathrm{C}$. There is limited clinical evidence of the real risks that youth athletes face when training and competing in the heat, but some recommendations can be made. The estimated average wet bulb globe temperature for Nanjing in August is $32^{\circ} \mathrm{C}$, which has been classified as a very high risk/stop play condition for heat illness and injury. Training and competing under extreme heat conditions could stress the thermoregulatory system and adversely affect health and performance. However, current guidelines appear to be inadequate or too conservative, and mostly focus on adult elite athletes. Therefore, proper preventive measures are warranted to reduce the risks of heat illness and injury. With proper heat acclimatization and monitoring, youth athletes can exercise reasonably well and safely in the heat. During the second Summer Youth Olympic Games in Nanjing, People's Republic of China, special attention should be devoted to athletes exposed to long and extensive sunny and hot conditions.

Keywords: youth sports, heat acclimatization, thermoregulation

\section{Introduction}

The second Summer Youth Olympic Games will take place August 16-28, 2014 in Nanjing, People's Republic of China. Approximately 3,600 youth athletes from 204 nations are expected to compete in 28 different sports under the motto "Share the Games, Share our Dreams". The Games will run during the peak of the summer, and Nanjing has been reported as one of the hottest cities in the People's Republic of China. Nanjing is located in eastern China, at the lower valley of Yangtze River, and has a humid subtropical climate. According to anecdotal reports, the nearby mountains hold the hot air in, and temperatures can reach extreme highs of $40^{\circ} \mathrm{C}$ during summer months. The average temperature is $28^{\circ} \mathrm{C}$, and average high and low temperatures are $32^{\circ} \mathrm{C}$ and $24^{\circ} \mathrm{C}$, respectively. The average relative humidity for the month of August is $81 \%$, with rain occurring occasionally and lasting on average 12 days. ${ }^{1}$

In 2012, the International Olympic Committee (IOC) Medical Commission published a consensus statement on the thermoregulatory challenges for Olympic and other high-level athletes. ${ }^{2}$ IOC Medical Commission, in collaboration with the International Sports Federations, has also issued a series of guidelines and preventive measures aimed to reduce the risks associated with training and competing under thermal stress conditions. ${ }^{2-5}$ However, no guidelines have been developed for youth athletes. 
Despite limited clinical evidence of the real risks that youth athletes face when training and competing in the heat, some recommendations can be made, eg, increase the time for recovery and reduce the number of contests per day in sameday contests; monitor the athletes closely, and encourage hydration and cooling strategies; schedule competition events for cooler times of the day; and cancel the events in case of extreme environmental conditions. ${ }^{6}$

Ambient air temperature, relative humidity, air motion, and the amount of radiant heat from the sun or other sources are the environmental factors that influence the risk of heat illness and injury. Recently, wet-bulb globe temperature (WBGT) - an index calculated from wet-bulb, dry-bulb, and black-globe temperatures - has been recognized as the gold-standard indicator of environmental heat stress. WBGT is now largely used in sports, as it possibly represents the best current measure available, particularly during hot and humid conditions. ${ }^{6}$ However, not all facilities have the proper equipment to calculate WBGT. To overcome this limitation, approximate WBGT values calculated based on shaded drybulb temperature and relative humidity may be used. ${ }^{7}$

Cut-off values for decision making are still an important topic of discussion. In most cases, the organizers of a sports event will follow the recommendations of the American College of Sports Medicine ${ }^{7}$ regarding the risk of heat illness and injury: "unrestricted" $\left(<22^{\circ} \mathrm{C}\right)$, "low risk" $\left(22^{\circ} \mathrm{C}-28^{\circ} \mathrm{C}\right)$, "high risk" $\left(28^{\circ} \mathrm{C}-30^{\circ} \mathrm{C}\right)$, "very high risk" $\left(30^{\circ} \mathrm{C}-32^{\circ} \mathrm{C}\right)$, and "stop play" $\left(>32^{\circ} \mathrm{C}\right)$. However, these recommendations address the potential risks for a broad range of athletes independently of their fitness level and acclimatization. It is not known whether the same recommendations apply to youth athletes exercising in the heat.

In the end, many sports events still happen regardless of WBGT guidelines or the recommendations for exercising in the heat. ${ }^{2-5}$ It is possible that current guidelines are too conservative, or that they fail to consider the specific risks of heat illness in sports.

\section{Discussion}

The estimated average WBGT for Nanjing in August is $32^{\circ} \mathrm{C},{ }^{1}$ which has been classified as a very high risk/stop play condition for heat illness and injury. ${ }^{7}$ The WBGT was calculated based on historical average temperature and relative humidity; it is only valid for full sunshine and light wind conditions, and it does not take into consideration the intensity of solar radiation and wind speed. An overestimation of thermal stress is likely, particularly in cloudy and windy conditions, and at night time and early morning when the sun is low or below the horizon. ${ }^{4}$ On the other hand, the temperatures in Nanjing can reach as high as $40^{\circ} \mathrm{C}$, ${ }^{1}$ which means that WBGT is likely to go above $32^{\circ} \mathrm{C}$. It is possible that during the second Summer Youth Olympic Games, athletes train and compete under extreme thermal stress conditions that could adversely affect their health and performance.

The responsibility for preparing the athletes to compete in the heat should be shared between event organizers, referees, medical staff, coaches, and the athletes themselves. According to the IOC, infrastructures should provide the solutions (ie, air-conditioned rooms, shaded areas, and cooling stations) to reduce heat stress and support the staff during training and competition. A comprehensive emergency action plan should be tested and prepared for any casualty. The scheduling of training and competitions should consider the time of the day when less heat stress and exposure is expected. ${ }^{2}$ Recently and for the first time in World Cup history, the organizers of the 2014 FIFA World Cup Brazil ${ }^{\mathrm{TM}}$ ordered water breaks if the temperature reached $32^{\circ} \mathrm{C}$ or higher. In Nanjing, referees and medical staff should also have the possibility of introducing official stoppages for hydration.

Special attention should be devoted to youth athletes competing outdoors multiple times on the same day with short resting times between rounds of play during hot-weather conditions (as in athletics or $3 \times 3$ basketball). ${ }^{6}$ Long and intense exposure to heat might challenge body fluid balance. ${ }^{6}$ Thus, young athletes competing in sports such as cycling, soccer, rugby, tennis, and triathlon might also be at increased risk.

With proper heat acclimatization, hydration, and monitoring during heat exposure, youth athletes can exercise reasonably well and safely in the heat. ${ }^{8,9}$ Most of the long-held beliefs concerning the higher vulnerability of the youth to heat stress might be overstated, and are not fully supported by scientific literature. However, during the Beijing 2008 Olympic Games, there were 27 cases of heat-related illness among workforce, public, and athletes. ${ }^{10}$ Interestingly, the average temperature during the Beijing 2008 Olympic Games was $25^{\circ} \mathrm{C}$, with high and low temperatures of $33^{\circ} \mathrm{C}$ and $20^{\circ} \mathrm{C}$, respectively; the relative humidity averaged $81 \% .{ }^{11}$ This means that the environmental conditions in Nanjing might prove even more challenging than in Beijing. Besides heat and humidity, several issues related to air pollution have been raised during the Beijing 2008 Olympic Games. ${ }^{12}$ Air pollution may negatively affect respiratory function and exercise performance, ${ }^{13}$ and more so if combined with high ambient temperatures. ${ }^{14,15}$ Special attention should be given to asthmatic participants or ozone-sensitive individuals who are at increased risk of lung inflammation when exposed to both heat 
and high ozone levels. ${ }^{13}$ In Beijing, the Chinese government has made unprecedented strides toward improving air quality during the Games. These measures resulted in a decrease in air pollutants around the Beijing area that were associated with an acute reduction in biomarkers of inflammation in young adults. ${ }^{16,17}$ Nanjing has typically low levels of pollution compared to Beijing, but recent episodes of severe air pollution have forced cancellation of classes at kindergartens and elementary and middle schools. ${ }^{18}$ Restrictions in traffic and industrial production are suggested around the time of the second Summer Youth Olympic Games in Nanjing. In an attempt to further minimize the adverse effects of air pollution and heat in health and performance, organizers, coaches, and athletes should follow local air quality forecasts ${ }^{13}$ and plan training sessions and competitions accordingly.

\section{Conclusion}

Youth athletes can exercise reasonably well and safely in the heat, but given the high temperatures that are expected to occur during the second Summer Youth Olympic Games in Nanjing, People's Republic of China, proper heat acclimatization, monitoring, and recovery is recommended. During training and competition, special attention should be devoted to athletes exposed to long and extensive sunny and hot conditions. If proper preventive measures are taken, the risk of heat illness and injury can be greatly reduced.

\section{Disclosure}

The authors report no conflicts of interest in this work.

\section{References}

1. Climatemps.com [homepage on the Internet]. Climate of Nanjing, China average weather. Available from: http:// www.nanjing.climatemps.com/index.php. Accessed June 20, 2014.

2. Bergeron MF, Bahr R, Bärtsch P, et al. International Olympic Committee consensus statement on thermoregulatory and altitude challenges for high-level athletes. Br J Sports Med. 2012;46(11):770-779.
3. Bahr R, Reeser JC. New guidelines are needed to manage heat stress in elite sports - The Fédération Internationale de Volleyball (FIVB) Heat Stress Monitoring Programme. Br J Sports Med. 2012;46(11): 805-809.

4. Grantham J, Cheung SS, Connes P, et al. Current knowledge on playing football in hot environments. Scand J Med Sci Sports. 2010; 20(Suppl 3):161-167.

5. Mountjoy M, Alonso JM, Bergeron MF, et al. Hyperthermicrelated challenges in aquatics, athletics, football, tennis and triathlon. Br J Sports Med. 2012;46(11):800-804.

6. Bergeron MF. Youth sports in the heat: recovery and scheduling considerations for tournament play. Sports Med. 2009;39(7):513-522.

7. [No authors listed]. Prevention of thermal injuries during distance running. Position stand. American College of Sports Medicine. Med J Aust. 1984;141(12-13):876-879.

8. Rivera-Brown AM, De Félix-Dávila RA. Hydration status in adolescent judo athletes before and after training in the heat. Int J Sports Physiol Perform. 2012;7(1):39-46.

9. Rowland T, Hagenbuch S, Pober D, Garrison A. Exercise tolerance and thermoregulatory responses during cycling in boys and men. Med Sci Sports Exerc. 2008;40(2):282-287.

10. Chen Z, Zhang YL, Wan LD, et al. [Analysis on characteristics of 802 emergency cases transported from venues of the Beijing 2008 Olympic Games]. Zhongguo Wei Zhong Bing Ji Jiu Yi Xue. 2010;22(1):32-35. Chinese.

11. Braniš M, Větvička J. PM10, ambient temperature and relative humidity during the XXIX Summer Olympic Games in Beijing: were the athletes at risk? Aerosol and Air Quality Research. 2010;10(2):102-110.

12. Milne CJ, Shaw MT. Travelling to China for the Beijing 2008 Olympic Games. Br J Sports Med. 2008;42(5):321-326.

13. Giles LV, Koehle MS. The health effects of exercising in air pollution. Sports Med. 2014;44(2):223-249.

14. Galloway SD, Maughan RJ. Effects of ambient temperature on the capacity to perform prolonged cycle exercise in man. Med Sci Sports Exerc. 1997;29(9):1240-1249.

15. Folinsbee LJ, Silverman F, Shephard RJ. Decrease of maximum work performance following ozone exposure. J Appl Physiol Respir Environ Exerc Physiol. 1977;42(4):531-536.

16. Lin $\mathrm{W}$, Huang $\mathrm{W}, \mathrm{Zhu} \mathrm{T}$, et al. Acute respiratory inflammation in children and black carbon in ambient air before and during the 2008 Beijing Olympics. Environ Health Perspect. 2011;119(10):1507-1512.

17. Rich DQ, Kipen HM, Huang W, et al. Association between changes in air pollution levels during the Beijing Olympics and biomarkers of inflammation and thrombosis in healthy young adults. JAMA. 2012;307(19):2068-2078.

18. Ramzy A. Air pollution shrouds eastern China. The New York Times. December 5, 2013. Available from: http://sinosphere.blogs.nytimes. com/2013/12/05/air-pollution-shrouds-eastern-china/?_php=true\&_ type $=$ blogs \&_r=0. Accessed June 20, 2014.

Open Access Journal of Sports Medicine

\section{Publish your work in this journal}

Open Access Journal of Sports Medicine is an international, peer-reviewed, open access journal publishing original research, reports, reviews and commentaries on all areas of sports medicine. The manuscript management system is completely online and includes a very quick and fair peer-review system. 